\title{
Taxonomic map of the schizophrenias, with special reference to puerperal psychosis
}

\author{
P HAYS
}

British Medical fournal, 1978, 2, 755-757

\section{Summary and conclusions}

Data collected by a single observer on 147 schizophrenic patients were subjected to clustering analysis. The results produced the hypothesis that schizophrenic illnesses directly after childbirth are a separate disease entity. This hypothesis was not disproved by experimental testing.

Several disease entities may be included in the term schizophrenia. If this is so, the methods used in generating and testing the hypothesis that puerperal schizophrenia is a separate disease may provide a systematic method of classifying the various illnesses.

\section{Introduction}

For want of a convincing classification into apparently homogeneous subgroups, those who investigate aspects of schizophrenia observe or test patients selected solely because they have been diagnosed as schizophrenic. Any specific investigation, but particularly one aimed at determining causation, may produce misleading conclusions if the term schizophrenia covers various illnesses. Our perennial inability to find a cause for schizophrenia lends credibility to Bleuler's original proposition that several disease entities are included in what he called the schizophrenias. ${ }^{1}$ If adopted, this working proposition calls for a systematic attempt at classification. A posteriori, natural classification may be achieved if based on many disparate features of a large and fair selection of subjects, provided that some method is available for analysing this mass of data.

\section{Patients and methods}

From 1963 to 1975 I collected data on a series of schizophrenic patients. In each case schizophrenia had been diagnosed by other consultants. All patients referred to me in this way were accepted. I looked after all patients personally for about five years. Patients with epilepsy or a history of drug abuse or alcoholism, or those who refused to undergo electroencephalography or who were adopted and did not know their families were excluded from the series but not from my care. A total of 147 patients were included in the study. As I expected that a method of analysing the voluminous data would become available, I collected details for each patient on the following items:

Department of Psychiatry, University of Alberta, Edmonton, Alberta T6G 2G3, Canada

P HAYS, MB, FRCPC, professor of psychiatry family history of psychiatric illnesses and personality deviations; personality; sexuality; social factors; physical stigmata; and illnesses and stressful events occurring during the year before symptoms of the first schizophrenic illness developed. I also noted the symptoms present at the height of the illness, any residual symptoms after treatment, treatment used, and details of the response. Each patient underwent electroencephalography; I read all traces in batches with the names obscured some time after the tests had been done, and reread them after a further interval. I interviewed 133 relatives and obtained the case notes of 61 affected relatives. If any item was recorded as present, I had observed or elicited it, and if any was recorded as absent then it had been sought, and not found. Of 123 items recorded, the following 52 were used in the analyses. Sex (1); age at onset of first psychiatric manifestations of fully developed schizophrenic syndrome (2). Other items were subdivided under the following headings.

Genetic-Family history of schizophrenia or bipolar affective illness in first- or second-degree relatives (3).

Premorbid personality - Inferiority feelings (4); suspiciousness (5); solitariness (6); obsessionality (7); anxiousness (8).

School or work record (9).

Electroencephalogram-Symmetric: $5-8 \mathrm{~Hz}$ (10); asymmetric $5-8 \mathrm{~Hz}(11)$.

Social and psychological stresses-Bereavement during six months before onset of psychiatric symptoms leading to schizophrenia (12); interest in mysticism or occultism during year before onset of psychiatric symptoms (13); whether native of country in which psychoses started (14); physical stigma (15); member of unpopular minority group (16); hostile environment, not otherwise specified (17).

Physical stresses-(All illnesses listed occurred during year before onset of psychiatric symptoms leading to schizophrenia, except for 23 a.) Pulmonary tuberculosis (18); unexplained abdominal pain (19); severe sore throat (20); severe influenza (21); concussion (22); childbirth during month before onset of psychiatric symptoms $(23 a)$ or menopause with hot flushes $(23 b)$.

Mode of onset-(All items listed were first psychiatric manifestations of fully developed schizophrenic syndrome.) Neurotic symptoms (24); loss of drive and efficiency (25); depressive symptoms (26); delusions of reference without hallucinations (27); hallucinations (28); thought disorder (29).

Syndrome at height of illness-Hallucinations: auditory (30); tactile (31); visual (32); taste or smell, or both (33). Preceptual distortions: auditory (34); tactile (35); visual (36); taste or smell, or both (37). Affect: depressed (38); elevated (39); anxious (40); flattened (41). Catatonic symptoms (42); passivity phenomena (43); thought disorder (44); primary delusions (45); secondary delusions (46); insomnia (47).

Residual symptoms-Depressed (48); apathetic (49).

Maintenance dosage-Phenothiazines (50); antidepressants (51).

Clustering analysis had evolved as I had hoped, and was used. No consensus exists about the ideal way to cause clusters to form, and results may vary between methods. I therefore used several methodsnamely, Carmichael's ${ }^{2}{ }^{3}$; and Centroid, Ward's, and McQuitty's (all from "Clustan"4). Since clustering will mislead if the data used or the patients observed do not constitute a fair sample, the methods were also tested on alternate items and on alternate patients, both moieties being clustered in each instance, to see if clusters remained consistent. 


\section{Results}

Some variations were inevitable, but three clusters formed fairly consistently and maintained a consistent relation with each other in the graphic outputs, of which a composite representation is shown in the figure; inconsistencies are detailed in table I. The "residuum" contains interesting subgroups, and is certainly not homogeneous-

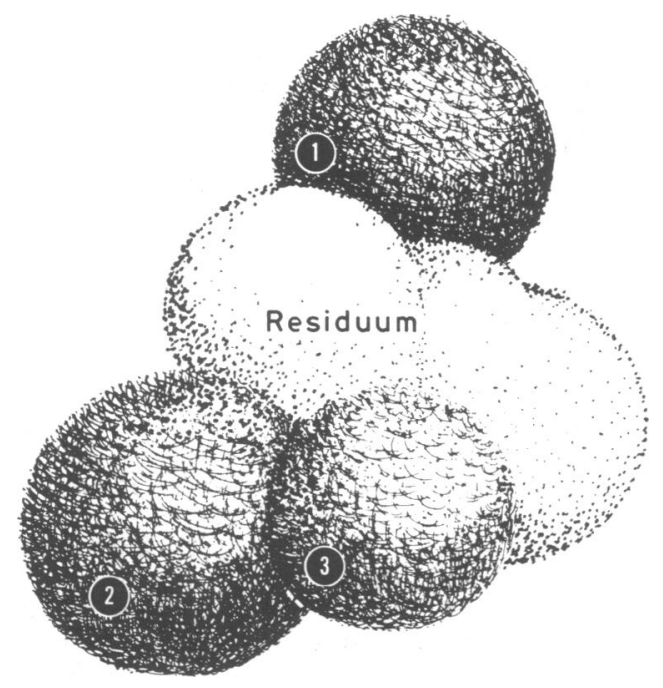

Composite representation of clustering produced by analysis of data on schizophrenic patients. Cluster 1: hallucinatory illness of paranoid symptomatology; cluster 2: variant of manic depression; cluster 3: puerperal schizophrenia. Residuum comprises about $65 \%$ of those studied.

TABLE I-Extent to which different methods of clustering were consistent in analysing data on 147 schizophrenic patients

\begin{tabular}{|c|c|c|c|c|c|c|c|}
\hline & & \multicolumn{2}{|c|}{ Carmichael } & \multicolumn{2}{|c|}{ Ward } & \multicolumn{2}{|c|}{ Centroid } \\
\hline & & In & Out & In & Out & In & Out \\
\hline \multicolumn{8}{|c|}{ Cluster No 1} \\
\hline McQuitty & $\left\{\begin{array}{l}\text { In } \ldots \\
\text { Out } \ldots\end{array}\right.$ & $\begin{array}{r}16 \\
3\end{array}$ & $\begin{array}{r}10 \\
118\end{array}$ & $\begin{array}{l}24 \\
10\end{array}$ & $\begin{array}{r}2 \\
111\end{array}$ & $\begin{array}{r}23 \\
3\end{array}$ & $\begin{array}{r}7 \\
114\end{array}$ \\
\hline Ward & $\left\{\begin{array}{l}\text { In } \ldots \\
\text { Out } \ldots\end{array}\right.$ & $\begin{array}{r}16 \\
3\end{array}$ & $\begin{array}{r}18 \\
110\end{array}$ & & & & \\
\hline Centroid & $\left\{\begin{array}{l}\text { In } \ldots \\
\text { Out } \ldots\end{array}\right.$ & $\begin{array}{r}19 \\
2\end{array}$ & $\begin{array}{r}11 \\
115\end{array}$ & $\begin{array}{r}27 \\
7\end{array}$ & $\begin{array}{r}3 \\
110\end{array}$ & & \\
\hline \multicolumn{8}{|c|}{ Cluster $\mathrm{No} 2$} \\
\hline McQuitty & $\left\{\begin{array}{l}\text { In } \ldots \\
\text { Out } \ldots\end{array}\right.$ & $\begin{array}{l}7 \\
5\end{array}$ & $\begin{array}{r}10 \\
125\end{array}$ & $\begin{array}{r}15 \\
2\end{array}$ & $\begin{array}{r}9 \\
121\end{array}$ & $\begin{array}{r}13 \\
4\end{array}$ & $\begin{array}{r}8 \\
122\end{array}$ \\
\hline Ward & $\left\{\begin{array}{l}\text { In } \ldots \\
\text { Out } . .\end{array}\right.$ & $\begin{array}{l}9 \\
3\end{array}$ & $\begin{array}{r}15 \\
120\end{array}$ & & & & \\
\hline Centroid & $\left\{\begin{array}{l}\text { In } \ldots \\
\text { Out } \ldots\end{array}\right.$ & $\begin{array}{l}7 \\
5\end{array}$ & $\begin{array}{r}14 \\
121\end{array}$ & $\begin{array}{r}16 \\
8\end{array}$ & $\begin{array}{r}5 \\
118\end{array}$ & & \\
\hline \multicolumn{8}{|c|}{ Cluster No 3} \\
\hline McQuitty & $\left\{\begin{array}{l}\text { In } \\
\text { Out } \ldots\end{array}\right.$ & $\begin{array}{l}6 \\
4\end{array}$ & $\begin{array}{r}3 \\
134\end{array}$ & $\begin{array}{l}7 \\
3\end{array}$ & $\begin{array}{r}2 \\
135\end{array}$ & $\begin{array}{l}8 \\
1\end{array}$ & $\begin{array}{r}2 \\
136\end{array}$ \\
\hline Ward & $\left\{\begin{array}{l}\text { In } \\
\text { Out } . .\end{array}\right.$ & $\begin{array}{l}8 \\
2\end{array}$ & $\begin{array}{r}2 \\
135\end{array}$ & & & & \\
\hline Centroid & $\left\{\begin{array}{l}\text { In } \\
\text { Out } . .\end{array}\right.$ & $\begin{array}{l}7 \\
3\end{array}$ & $\begin{array}{r}3 \\
134\end{array}$ & $\begin{array}{l}9 \\
1\end{array}$ & $\begin{array}{r}1 \\
136\end{array}$ & & \\
\hline
\end{tabular}

The case that is most likely to be the outcome of chance (cluster No 2, Carmichael $v$ Centroid) has a $\mathrm{P}$ value of $<0 \cdot 0005$.

that is, it does not represent some "core" illness of "true" schizophrenia. It subclustered inconsistently, so that it would be premature to offer a detailed analysis of it; but an investigation I undertook from a different viewpoint implies that it can be subdivided on the basis of genetic and electroencephalographic criteria. ${ }^{5}$

As is well known, clustering methods as used here merely generate hypotheses. Care in collecting the data and other methodological precautions only make it more likely that the hypotheses will be of value. The hypotheses cannot be assessed by the consistency with which they form or by any similar means, and, in particular, they cannot be assessed by using any of the data that engendered them. They must be examined on their own merits, and tested separately.

Cluster 1-Hallucinatory illness of paranoid symptomatology. These patients' illnesses were heralded by ideas of reference, precipitated by self-styled "misdemeanours," which caused shame and arose in a setting of personal insecurity and inferiority feelings. The fully developed syndrome consisted of auditory hallucinations and secondary delusions, but thought disorder was absent or minimal, while catatonic features, major affective disorders, and passivity feelings were absent. Family histories were negative for schizophrenia. This seems to correspond to the "syndrome of sensitive delusions of reference" described by Kretschmer, ${ }^{6}$ and thus is not new.

Cluster 2-Variant of manic depression. The syndrome generally started with depression, followed by a catatonic illness with elevation of mood or depression, or both; thought disorder was prominent and auditory hallucinations were common, but other hallucinations and passivity feelings were less so. There was a bipolar affective aftermath, responsive to lithium treatment. Because family histories of (bipolar) manic depression and schizophrenia were included in the same item when clustering was done, the subsequent finding that manic depression predominated in the family histories of these patients supports the implicit hypothesis that an entity is being isolated. Nevertheless, a variant of manic depression was shown to be able to mimic schizophrenia in $1940,{ }^{7}$ and thus, though the distinction has only gradually become generally accepted, it is not new.

TABLE II-Items with most discriminating power in interpreting results of cluster analysis

\begin{tabular}{|c|c|c|c|c|c|}
\hline & Variable* & Score & $\begin{array}{c}\text { Function } \\
1\end{array}$ & $\begin{array}{c}\text { Function } \\
2\end{array}$ & $\begin{array}{c}\text { Function } \\
3\end{array}$ \\
\hline \multicolumn{6}{|c|}{ Standardised discriminant function coefficients } \\
\hline $\begin{aligned} \text { Item } 23 \\
\Rightarrow \quad 16\end{aligned}$ & $\begin{array}{l}\text { Physical stress: childbirth } \\
\text { Social and psychological } \\
\text { stress: unpopular }\end{array}$ & $|0-1|$ & 0.86732 & 0.05708 & 0.01074 \\
\hline $\begin{array}{l}26 \\
27\end{array}$ & $\begin{array}{l}\text { minority } \\
\text { Mode of onset: depressive } \\
\text { Mode of onset: delusions }\end{array}$ & $\begin{array}{l}0-1 \\
0-1\end{array}$ & $\begin{array}{l}0.03388 \\
0.02325\end{array}$ & $\begin{array}{r}0.40907 \\
-0.33037\end{array}$ & $\begin{array}{l}-0.02606 \\
-0.87798\end{array}$ \\
\hline & of reference & $0-1$ & -0.03547 & 0.42822 & $-0 \cdot 22574$ \\
\hline $\begin{array}{l}\dddot{4} \\
\text { ” } 32\end{array}$ & $\begin{array}{l}\text { Aftermath: depressed } \\
\text { Visual hallucinations }\end{array}$ & $\begin{array}{l}0-5 \\
0-5\end{array}$ & $\begin{array}{r}0.18131 \\
-0.19529\end{array}$ & $\begin{array}{l}-0.02294 \\
-0.08156\end{array}$ & $\begin{array}{l}0.12419 \\
0.23007\end{array}$ \\
\hline ” 34 & $\begin{array}{l}\text { Perceptual distortions: } \\
\text { auditory }\end{array}$ & $0-5$ & 0.05576 & 0.28907 & -0.21827 \\
\hline ” 42 & $\begin{array}{l}\text { Catatonic symptoms } \\
\text { Primary delusions }\end{array}$ & $\begin{array}{l}0-5 \\
0-5\end{array}$ & $\begin{array}{l}0.18372 \\
0.04761\end{array}$ & $\begin{array}{l}-0.24440 \\
-0.32807\end{array}$ & $\begin{array}{l}0.00436 \\
0 \cdot 26200\end{array}$ \\
\hline 50 & $\mid \begin{array}{c}\text { Maintenance dosage: } \\
\text { phenothiazines } \dagger\end{array}$ & & -0.06274 & $\mid-0.23063$ & $0 \cdot 11885$ \\
\hline \multicolumn{6}{|c|}{ Centroids of clusters in reduced space } \\
\hline $\begin{array}{rr}\text { Cluster } 1 \\
\Rightarrow & 2 \\
\text { Residuum } & 3 \\
\text { Reside }\end{array}$ & & & $\begin{array}{r}-0.36668 \\
0 \cdot 18625 \\
3 \cdot 47536 \\
-0.24651\end{array}$ & $\begin{array}{r}1.61660 \\
-1.03395 \\
0.31284 \\
-0.27894\end{array}$ & $\mid \begin{array}{r}-0.44665 \\
-1.91641 \\
0.28341 \\
0.32755\end{array}$ \\
\hline
\end{tabular}

*Fuller details given in text.

tScored according to dosage-for example, $100 \mathrm{mg}$ chlorpromazine: score $=1$. Investigators wishing to place their own patients in the appropriate cluster (or then using the function equations when they are compared with the Centroid positions.

Cluster 3-Puerperal schizophrenia. Illnesses started within a few days of delivery. Thought disorder, catatonic symptoms, hectic mood changes, visual misrecognition, auditory hallucinations, and varying delusions were characteristic of the illness. The aftermath, if any, was (unipolar) depressive. Two patients whose illnesses were not puerperal were included in the cluster, but one had a mother who had had puerperal schizophrenia, while the other had a recurrence of her original nonpuerperal illness during her first puerperium.

Individuals present in each cluster in three or more of the sets of clustering results were identified. The three combined clusters so designated, together with their residuum, were subjected to stepwise discriminant analysis ${ }^{8}$ to determine the discriminating variables. The 10 variables with the most discriminating power are shown in table II, together with their standardised discriminant function coefficients and Centroid data.

\section{Discussion}

The hypothesis that puerperal schizophrenia is a separate disease is new, at least in the sense that texts have denied its truth throughout this century, though it has been noted that 
while the risk of puerperal psychosis recurring during subsequent deliveries is rather high, the risks of parturition for patients whose schizophrenia developed without relation to childbirth do not seem to be high. ${ }^{9} 10$

The hypothesis may be tested by studying family histories: any entity with even a partial basis in genetic predisposition should run true, and thus affected relatives should have disproportionately many puerperal illnesses. Since puerperal schizophrenia has not been regarded as an entity, relatives' puerperal illnesses are unlikely always to be so designated, thus reducing the chance of finding support for the hypothesis. Nevertheless, the matter may be approached indirectly: since puerperal schizophrenia is associated with an aspect of femininity the affected relatives of puerperal schizophrenias should be predominantly female and in this respect should differ from those of non-puerperal female schizophrenics and, to an even greater extent, from those of male schizophrenics.

I looked at appropriate records. At some hospitals only those of puerperal patients were reviewed, while at a mental hospital more records of males than of females were reviewed. Thus the absolute numbers of relatives to be found in the three categories are not those that would be found in a fair sample, which I mention to avoid false incidental conclusions being drawn from these results: affected relatives of puerperal schizophrenics, nine male, 30 female; of non-puerperal female schizophrenics, 27 male, 44 female; and of male schizophrenics, 45 male, 52 female $\left(\chi^{2}=6.40 ; P<0.05\right)$. If the affected relatives of puerperal schizophrenics are compared with all other affected relatives women are overrepresented (Fishers's exact test: $P<0.02$ ). Of the 39 schizophrenics related to puerperal schizophrenics, nine were recorded as puerperal; of the 147 schizophrenics under study, seven were puerperal (a proportion similar to those reported elsewhere ${ }^{11}$, so that puerperal schizophrenia seems to arise relatively frequently among the relatives of puerperal schizophrenics (Fishers's exact test: $\mathrm{P}<0.005$ ). The method used to test this hypothesis, unlike that used to generate it, is simple and may easily be reapplied by other workers.

The hypothesis that puerperal schizophrenia is the paradigm of a true entity commands attention firstly because it arose from a study specifically designed to allow minimally contaminated induction, and secondly because it is not disproved by experimental testing.

I thank Dr D Curran for encouragement and support; Miss $\mathrm{K}$ Villars for administrative help; and Drs T Overton, $M$ Grace, J Linders, V Gupta, J W Carmichael, and Mrs D Gupta and Mr B Pinchbeck for help with analysis and computing.

Psychiatric colleagues or physicians interested in numerical taxonomy are welcome to review or analyse the original data.

\section{References}

${ }^{1}$ Bleuler, E, Dementia Praecox or the Group of Schizophrenias, trans J Zinkin. New York, International Universities Press, 1950.

2 Carmichael, J W, George, J A, and Julius, R S, Systematic Zoology, 1966, $17,144$.

${ }^{3}$ Carmichael, J W, Julius, R S, and Martin, P M D, Nature, 1965, 208, 544.

4 Wishart, D, Fortran II programmes for 8 methods of cluster analysis (CLUSTAN 1). Computer Contribution 39, State Geological Survey. Lawrence, University of Kansas, 1969.

${ }^{5}$ Hays, P, Fournal of Neurology, Neurosurgery and Psychiatry, 1977, 40, 753. ${ }^{6}$ Kretschmer, E, A Textbook of Medical Psychology, trans E B Strauss. London, Hogarth, 1952.

7 Kant, O, Psychiatric Quarterly, 1940, 14, 676.

${ }^{8} \mathrm{Nie}, \mathrm{N}$ H, et al, SPS S: Statistical Package for the Social Sciences, 2nd edn. Toronto, McGraw-Hill, 1975.

${ }^{9}$ Martin, M E, British Medical fournal, 1958, $2,773$.

10 Yarden, P E, Max, D M, and Eisenbach, Z, British fournal of Psychiatry, $1966,112,491$

${ }^{11}$ Karnosh, L J, and Hope, J M, American fournal of Psychiatry, 1937, 94, 537.

(Accepted 23 May 1978)
Do herpes zoster vesicles contain infective virus particles and, if so, can they cause chickenpox or shingles in contacts?

Shingles results from reactivation of varicella-zoster virus that has remained latent after primary infection (chickenpox), usually in childhood. Vesicles contain infectious virus, and susceptible persons exposed to patients with shingles may contract chickenpox (varicella) but not, of course, shingles (zoster) since this can result only from reactivation of endogenous virus. Varicella-zoster virus is extremely ontagious, and therefore strict precautions to prevent cross-infection must be taken in hospital to ensure that infection is not transmitted to susceptible persons who are immunocompromised-for example, patients with acute leukaemia or those being treated with cytotoxic drugs or corticosteroids. Such patients may experience severe and often fatal infections.

Should a patient with rheumatoid arthritis of the knee restrict his walking?

Patients with active synovitis and minor erosions of leg joints should avoid excessive physical activity, particularly if increased swelling and stiffness are noted afterwards. Pronounced erosive changes are usually associated with instability arising from ligamentous laxity and cartilaginous loss. Weight bearing should be reduced to essentials, while quadriceps wasting is counteracted by regular static exercises. Severe unilateral instability can benefit from a detachable polyethylene cylinder.

Is there any alternative method for treating third-degree piles other than surgical treatment?

In running a large rectal clinic for many years I have found that it is only exceptionally that haemorrhoids need surgery. Most patients with third-degree piles get considerable relief of their symptoms simply by injections with 5\% phenol in almond oil. The secret is to use up to $10 \mathrm{ml}$ at one session. There is considerable shrinkage of the piles and control of bleeding. The patient will readily accept the inconvenience of a few skin tags provided he knows that surgery is not required.

Is there any recorded evidence of brain damage subsequent to polio vaccination given by injection in the 1959-62 period? Have all cases of brain damage said to be due to whooping-cough vaccination, which are now being cited as evidence for the damaging effect of this vaccine, actually been proved from records not to be associated with injectable polio vaccine?

There is no known causal association between injected killed polio vaccine and brain damage. Because encephalopathy not uncommonly presents in infancy, one would expect some cases by chance to be time-related to the polio vaccination, as for other vaccines given in infancy.

\section{Has goats' milk any place in modern therapeutics?}

The nutritional content of goats' milk is very much the same as that of cows' milk in its content of protein, fat, lactose, vitamin, and mineral elements. There is thus no nutritional advantage of the one over the other. On the other hand, although many babies and young children are allergic to the protein of cows' milk, most of these are not allergic to goats' milk. For such children, therefore, goats' milk is a reasonable alternative to cows' milk, although there are now many special proprietary milks available that are equally useful. Since the carbohydrate of goats' milk, like that of the milk of all mammals, consists of lactose, it is not suitable for individuals who suffer from lactose intolerance. 